\title{
What Triggers Oxygen Loss in Oxygen Redox Cathode Materials?
}

\author{
Robert A. House, ${ }^{\dagger}$ Urmimala Maitra, ${ }^{\dagger, \nabla}$ Liyu Jin, ${ }^{\dagger}{ }^{\circledR}$ Juan G. Lozano, ${ }^{\dagger}$ U James W. Somerville, ${ }^{\dagger ®}$
} Nicholas H. Rees, ${ }^{\S}$ Andrew J. Naylor, ${ }^{\|}$Laurent C. Duda, ${ }^{\perp}$ Felix Massel, ${ }^{\perp}$ Alan V. Chadwick, ${ }^{\#}$ Silvia Ramos," David M. Pickup," Daniel E. McNally, ${ }^{\text {IL }}$ Xingye Lu, ${ }^{\text {TI }}$ Thorsten Schmitt, ${ }^{\text {II }}$ Matthew R. Roberts, ${ }^{\dagger}$ and Peter G. Bruce ${ }^{* \dagger, \ddagger, \S}$

${ }^{\dagger}$ Department of Materials, University of Oxford, Parks Road, Oxford OX1 3PH, U.K.

${ }^{\ddagger}$ The Faraday Institution and ${ }^{\S}$ Department of Chemistry, University of Oxford, Mansfield Road, Oxford OX1 3TA, U.K.

"Department of Chemistry, Ångström Laboratory, Uppsala University, Box 538, Uppsala SE-75121, Sweden

${ }^{\perp}$ Department of Physics and Astronomy, Division of Molecular and Condensed Matter Physics, Uppsala University, Box 516, Uppsala S-751 20, Sweden

${ }^{\#}$ School of Physical Sciences, University of Kent, Canterbury, Kent CT2 7NH, U.K.

IIPhoton Science Division, Swiss Light Source, Paul Scherrer Institut, Villigen PSI CH-5232, Switzerland

Supporting Information

ABSTRACT: It is possible to increase the charge capacity of transitionmetal (TM) oxide cathodes in alkali-ion batteries by invoking redox reactions on the oxygen. However, oxygen loss often occurs. To explore what affects oxygen loss in oxygen redox materials, we have compared two analogous Na-ion cathodes, $\mathrm{P} 2-\mathrm{Na}_{0.67} \mathrm{Mg}_{0.28} \mathrm{Mn}_{0.72} \mathrm{O}_{2}$ and P2$\mathrm{Na}_{0.78} \mathrm{Li}_{0.25} \mathrm{Mn}_{0.75} \mathrm{O}_{2}$. On charging to $4.5 \mathrm{~V},>0.4 e^{-}$are removed from the oxide ions of these materials, but neither compound exhibits oxygen loss. $\mathrm{Li}$ is retained in $\mathrm{P} 2-\mathrm{Na}_{0.78} \mathrm{Li}_{0.25} \mathrm{Mn}_{0.75} \mathrm{O}_{2}$ but displaced from the TM to the alkali metal layers, showing that vacancies in the TM layers, which also occur in other oxygen redox compounds that exhibit oxygen loss such as $\mathrm{Li}\left[\mathrm{Li}_{0.2} \mathrm{Ni}_{0.2} \mathrm{Mn}_{0.6}\right] \mathrm{O}_{2}$, are not a trigger for oxygen loss. On charging at $5 \mathrm{~V}, \mathrm{P} 2-\mathrm{Na}_{0.78} \mathrm{Li}_{0.25} \mathrm{Mn}_{0.75} \mathrm{O}_{2}$ exhibits oxygen loss, whereas $\mathrm{P} 2-\mathrm{Na}_{0.67} \mathrm{Mg}_{0.28} \mathrm{Mn}_{0.72} \mathrm{O}_{2}$ does not. Under these conditions, both $\mathrm{Na}^{+}$and $\mathrm{Li}^{+}$are removed from $\mathrm{P} 2-\mathrm{Na}_{0.78} \mathrm{Li}_{0.25} \mathrm{Mn}_{0.75} \mathrm{O}_{2}$, resulting in underbonded oxygen (fewer than 3 cations coordinating oxygen) and surface-localized $\mathrm{O}$ loss. In contrast, for $\mathrm{P} 2-\mathrm{Na}_{0.67} \mathrm{Mg}_{0.28} \mathrm{Mn}_{0.72} \mathrm{O}_{2}$, oxygen remains coordinated by at least $2 \mathrm{Mn}^{4+}$ and $1 \mathrm{Mg}^{2+}$ ions, stabilizing the oxygen and avoiding oxygen loss.

\section{INTRODUCTION}

The energy density of lithium-ion batteries is limited by the capacity to store charge at the cathode. Typically the cathode is a lithium transition-metal (TM) oxide, for example, $\mathrm{LiMn}_{2} \mathrm{O}_{4}$, in which removal and reinsertion of $\mathrm{Li}^{+}$on charge-discharge is charge compensated by redox reactions on the TM ions, in this case $\mathrm{Mn}^{3+/ 4+}$. Recent studies have shown that it is possible to increase charge storage by invoking redox reactions on the oxide ions. $^{2-11}$ The most common examples are the so-called lithium-rich layered compounds, such as $\mathrm{Li}\left[\mathrm{Li}_{0.2} \mathrm{Ni}_{0.2} \mathrm{Mn}_{0.6}\right]$ $\mathrm{O}_{2}{ }^{12}$ and $\mathrm{Li}\left[\mathrm{Li}_{0.2} \mathrm{Ni}_{0.13} \mathrm{Co}_{0.13} \mathrm{Mn}_{0.54}\right] \mathrm{O}_{2}{ }^{5}$ These 3d TM materials were recently joined by examples from the $4 \mathrm{~d}$ and 5d series, for example, $\mathrm{Li}_{2} \mathrm{RuO}_{3}, \mathrm{Li}_{2} \mathrm{IrO}_{3}\left(\mathrm{Li}\left[\mathrm{Li}_{1 / 3} \mathrm{M}_{2 / 3}\right] \mathrm{O}_{2} ; \mathrm{M}\right.$ $=\mathrm{Ru}$ or Ir). ${ }^{7,13,14}$ The Li-rich materials contain enough $\mathrm{Li}^{+}$to utilize the capacity of the TM and $\mathrm{O}$ redox, reaching capacities in excess of $300 \mathrm{~mA} \mathrm{~h} \mathrm{~g}^{-1}$, compared with approx. $200 \mathrm{~mA} \mathrm{~h}$ $\mathrm{g}^{-1}$ for conventional cathodes that do not involve $\mathrm{O}$ redox. $\mathrm{O}$ redox has also been observed in sodium-rich compounds such as $\mathrm{Na}_{2} \mathrm{RuO}_{3}$ and $\mathrm{Na}_{2} \mathrm{IrO}_{3}$. ${ }^{6,15-17}$ However, excess alkali metal ions (i.e., $\mathrm{Li}$ and $\mathrm{Na}$ in the $\mathrm{TM}$ layer) are not essential to observe $\mathrm{O}$ redox, as we showed recently in $\mathrm{Na}_{0.67} \mathrm{Mg}_{0.28} \mathrm{Mn}_{0.72} \mathrm{O}_{2}$. ${ }^{18}$

In the majority of compounds that exhibit excess capacity due to the contribution from $\mathrm{O}$ redox, loss of $\mathrm{O}$ from the lattice also occurs. ${ }^{5-8,12,19,20}$ During our studies of P2$\mathrm{Na}_{0.67} \mathrm{Mg}_{0.28} \mathrm{Mn}_{0.72} \mathrm{O}_{2}$, we observed that $\mathrm{O}$ loss does not occur, prompting the question what determines $\mathrm{O}$ loss?

To explore what triggers $\mathrm{O}$ loss, we have prepared the alkalirich analogue of $\mathrm{P} 2-\mathrm{Na}_{0.67} \mathrm{Mg}_{0.28} \mathrm{Mn}_{0.72} \mathrm{O}_{2}$ (NMMO) by replacing $\mathrm{Mg}$ with $\mathrm{Li}$ to form $\mathrm{P} 2-\mathrm{Na}_{0.78} \mathrm{Li}_{0.25} \mathrm{Mn}_{0.75} \mathrm{O}_{2}$ (NLMO), whose TM layer structure and composition are analogous to Li-rich compounds. $\mathrm{Li}^{+}$is expected to be more mobile than $\mathrm{Mg}^{2+}$ permitting exploration of the influence of the cation mobility on $\mathrm{O}$ loss. P-type $\mathrm{Na}_{x} \mathrm{MnO}_{2}$ compounds with a partially Li-substituted TM layer have been reported previously, including $\mathrm{P} 2-\mathrm{Na}_{5 / 6} \mathrm{Li}_{1 / 4} \mathrm{Mn}_{3 / 4} \mathrm{O}_{2},{ }^{21} \mathrm{P} 2$ $\mathrm{Na}_{0.6} \mathrm{Li}_{0.2} \mathrm{Mn}_{0.8} \mathrm{O}_{2},{ }^{22}$ and P3-type $\mathrm{Na}_{0.6} \mathrm{Li}_{0.2} \mathrm{Mn}_{0.8} \mathrm{O}_{2},{ }^{23,24}$

Received: January 17, 2019

Revised: April 4, 2019

Published: April 5, 2019 
although no definitive indication of $\mathrm{O}$ loss has been reported in these cases. Powder X-ray diffraction (PXRD) showed that the structural properties of NMMO, namely, the honeycomb ordering in the TM-layer and P2-type structure (i.e., $\mathrm{Na}$ in prismatic sites and having $\mathrm{ABBA}$ arrangement of the O-lattice, as shown in Figure 1) with $\mathrm{P}_{3}$ symmetry, are retained in NLMO.

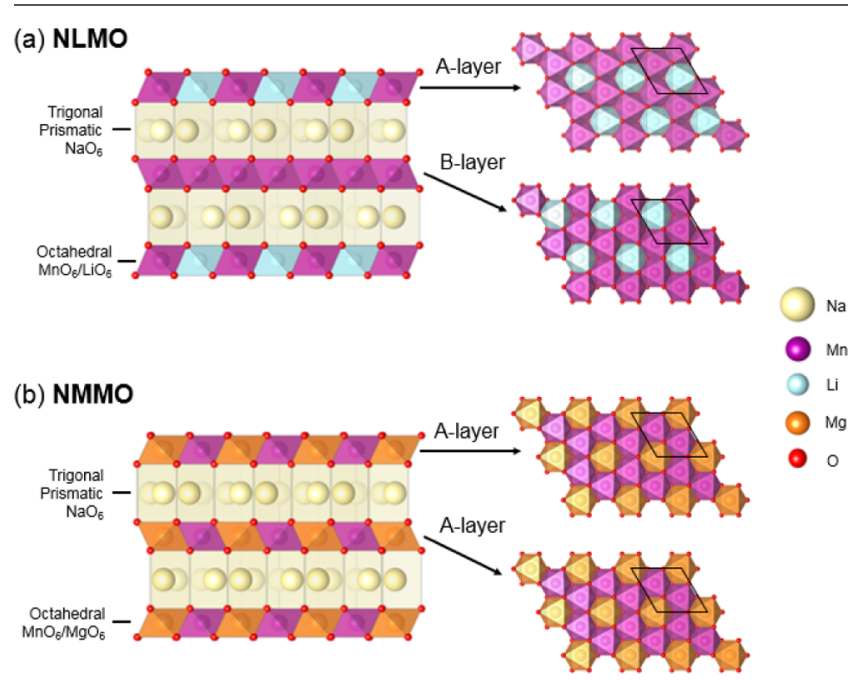

Figure 1. Schematic illustration of P2-type (a) $\mathrm{Na}_{0.78}\left[\mathrm{Li}_{0.25} \mathrm{Mn}_{0.75}\right] \mathrm{O}_{2}$ (NLMO) and (b) $\mathrm{Na}_{0.67}\left[\mathrm{Mg}_{0.28} \mathrm{Mn}_{0.72}\right] \mathrm{O}_{2}$ (NMMO). Right hand panels in each shows the $\sqrt{3} a \times \sqrt{3 a} a$-type superlattice ordering in the TM layer and the stacking sequences of two adjacent $\mathrm{TMO}_{2}$ layers. While NLMO shows an AB-type stacking sequence of the TM layers, NMMO shows an AA-type sequence according to the notation assigned by Yabuuchi et al. ${ }^{21}$

On charging to $4.5 \mathrm{~V}, 0.4 e^{-}$are removed from the oxide ions in NMMO and $0.53 e^{-}$in NLMO, but no O loss is observed in either case. The $\mathrm{Li}^{+}$ions in NLMO are retained in the structure but displaced from the TM to the alkali metal layers. $\mathrm{Li}^{+}$ions are also lost from the TM layers in materials that do exhibit $\mathrm{O}$ loss, for example, $\mathrm{Li}\left[\mathrm{Li}_{0.2} \mathrm{Ni}_{0.2} \mathrm{Mn}_{0.6}\right] \mathrm{O}_{2}{ }^{12}$ and $\mathrm{Li}\left[\mathrm{Li}_{0.2} \mathrm{Ni}_{0.13} \mathrm{Co}_{0.13} \mathrm{Mn}_{0.54}\right] \mathrm{O}_{2}$. ${ }^{5}$ Our results show that movement of $\mathrm{Li}^{+}$out of the TM layer is not a trigger for $\mathrm{O}$ loss. Instead, $\mathrm{O}$ loss can be triggered by charging under more severely oxidizing conditions, at $5 \mathrm{~V}$, but only for NLMO, not NMMO. Under these conditions, both $\mathrm{Na}^{+}$and $\mathrm{Li}^{+}$are removed from NLMO and lattice oxygen is lost from the surface of the electrode. This is due to a deficiency of alkali ions, $\mathrm{Na}^{+}$and $\mathrm{Li}^{+}$, leading to underbonding, that is, fewer than three cations coordinating $\mathrm{O}$, and as a consequence instability of $\mathrm{O}$ in the lattice. For NMMO, $\mathrm{Na}^{+}$is removed but $\mathrm{Mg}^{2+}$ retained. The much lower mobility of $\mathrm{Mg}^{2+}$ means that at least three cations coordinate $\mathrm{O}\left(2 \mathrm{Mn}^{4+}\right.$ and $\left.1 \mathrm{Mg}^{2+}\right)$, even at the surface, avoiding underbonding and mitigating $\mathrm{O}$ loss.

\section{RESULTS}

2.1. Pristine Material. P2-type NMMO was prepared by a solid-state reaction and characterized as described in our earlier work. ${ }^{18}$ We found that the P2-type NLMO with nominal composition $\mathrm{Na} / \mathrm{Li} / \mathrm{Mn}=0.78: 0.25: 0.75$ was the closest to NMMO that could be synthesized while retaining the P2-structure, in agreement with earlier reports by Yabuuchi et al. ${ }^{21}$ Details of the synthesis are provided in the Supporting Information. The P2 structure with in-plane honeycomb ordering was confirmed by PXRD (Figure S1) and the chemical composition with inductively coupled plasma-optical emission spectroscopy (ICP-OES) (Table S3). Superconducting quantum interference device (SQUID) measurements indicate a Mn-oxidation state of +3.9 , which is in line with expectations (see Figure S2).

Detailed structural analysis of NLMO was carried out using Rietveld profile fitting to a NPD pattern (see Figure S3 and Table S1). ${ }^{21}$ Figure 1 shows schematic representations of the structures. The stacking sequence of the TM layers of NLMO varies from that of NMMO, determined previously. ${ }^{21,25}$ In $\mathrm{NLMO}$, the honeycomb layers are stacked in an offset arrangement such that the $\mathrm{Li}$ are not aligned in the $\mathrm{c}$ axis direction (inset in Figure 1a). In contrast, in NMMO, the honeycomb layers line up to give columns of $\mathrm{Mg}$, as shown in inset Figure 1b. The diffraction data obtained for these compounds are similar to the simulated and experimental PXRD patterns shown by Yabuuchi et al. who assigned these stacking arrangements as AB- and AA-type, respectively. ${ }^{21}$ This should not be confused with Delmas' ABBA notation which refers to the stacking sequence of O layers. ${ }^{26}$ Annular-dark field scanning-transmission electron microscopy (ADF-STEM) images collected on the NLMO and NMMO samples confirm directly the presence of honeycomb ordering and the different stacking sequences (Figure S4). SEM images (Figure S5) of the samples show crystalline disc-shaped particles of $1-3 \mu \mathrm{m}$ diameter and $0.2-2 \mu \mathrm{m}$ thickness.

2.2. Electrochemistry. Details of electrode preparation and cell assembly are discussed in the Supporting Information. Typical galvanostatic charge-discharge curves of NLMO electrodes are shown in Figure 2. The first charge can be

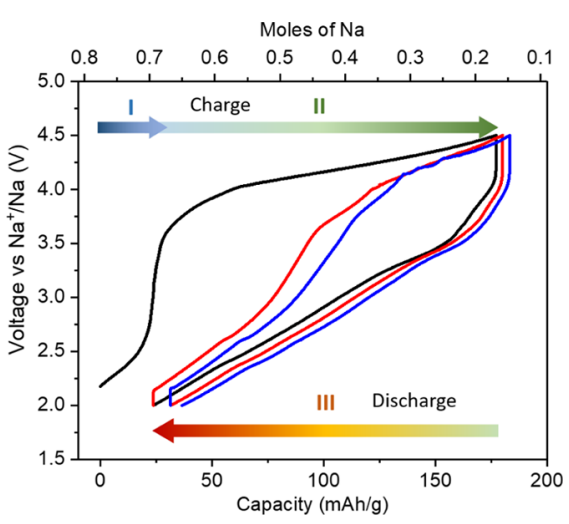

Figure 2. Galvanostatic charge-discharge curves for $\mathrm{Na}_{0.78}\left[\mathrm{Li}_{0.25} \mathrm{Mn}_{0.75}\right] \mathrm{O}_{2}$ that show the first three cycles (black, red, and blue from the first to the third cycle, respectively) at a rate of 10 $\mathrm{mA} \mathrm{g}{ }^{-1}$. Indicated with arrows are two distinct regions on charging, the first (I) corresponds to approximately the capacity expected from oxidation of $\mathrm{Mn}$ and the second (II) to additional capacity from anionic charge compensation. A third (III) region indicates the discharge. ICP confirmed $\mathrm{Na}$ is extracted but not $\mathrm{Li}$.

divided into two regions. The initial region of $\sim 20 \mathrm{~mA} \mathrm{~h} \mathrm{~g}$ (region I) can be accounted for by oxidation of the small amount of $\mathrm{Mn}^{3+}$ present in the sample, as observed from SQUID measurements. The charge passed at the end of region I would be consistent with all of the Mn being oxidized to the +4 oxidation state. In region II an additional $\sim 0.53 \mathrm{~mol}$ of $\mathrm{Na}$ can be removed accounting for overcapacity of $>140 \mathrm{~mA} \mathrm{~h} \mathrm{~g}^{-1}$. ICP measurements confirmed that $\mathrm{Na}$, not $\mathrm{Li}$, was extracted during charging, however $\mathrm{Li}$ is displaced from the TM layers, 
as discussed below. The material shows a discharge capacity of $\sim 150 \mathrm{~mA} \mathrm{~h} \mathrm{~g}^{-1}$. We collected operando PXRD data along the first cycle (Figure S6) confirming the single phase behavior of this material matching the observed sloping charge profile. There is a gradual increase in the c-lattice parameter and small decrease of the a-parameter, in line with deintercalation of $\mathrm{Na}^{+}$, the expansion of the interlayer distance is due to the increasing $\mathrm{O}-\mathrm{O}$ repulsions in the absence of $\mathrm{Na}$. At high states of charge, the peak profiles for the $00 l$ lines are significantly broadened indicating the formation of layer stacking faults. Our results are in agreement with Yabuuchi et al. who also did not observe a transition to crystalline domains of $\mathrm{O} 2 / \mathrm{OP} 4$ phase at the end of charge in P2-type $\mathrm{Na}_{0.83} \mathrm{Li}_{0.25} \mathrm{Mn}_{0.75} \mathrm{O}_{2}{ }^{21}$ However, as discussed later, there is evidence of some O-type stacking faults at high states of charge.

2.3. Oxygen Hole States. To study the electronic structure of NLMO, spectroscopic studies were carried out utilizing $\mathrm{Mn}$ and $\mathrm{O}$ X-ray absorption spectroscopy (XAS) and resonant inelastic X-ray scattering (RIXS) on the O K-edge. Ex situ Mn K-edge X-ray absorption near edge structure (XANES) measurements carried out on samples at various states of charge and discharge are shown in Figure S7 and a detailed description is provided in the Supporting Information. The results show similar changes to those which were observed for the NMMO previously, ${ }^{18}$ indicating that the Mn-oxidation state does not exceed +4 and that on discharge the manganese is not reduced significantly beyond the oxidation state of the starting material.

Over the first cycle, Figure 3a, substantial changes are observed in the $\mathrm{O}$ K-edge spectra (Figure $3 \mathrm{~b}$ ). The pre-edge represents transitions from $\mathrm{O} 1 \mathrm{~s}$ orbitals to empty states just above the Fermi level composed of empty Mn 3d states hybridized with $\mathrm{O} 2 \mathrm{p}$ states. The area under the pre-edge region $(528-532 \mathrm{eV})$ correlates with the available empty states. The pre-edge area increases and decreases linearly during charge and discharge accompanying oxidation of both manganese and oxygen and in line with our observations for NMMO, Figure 3c. Although O XAS alone cannot prove that electron holes on $\mathrm{O}$ are present, because we observe no changes in the Mn XANES beyond $\mathrm{Mn}^{4+}$, we conclude that the additional hole states we observe $(\sim 0.53$ per formula unit NLMO) must be located on the oxide ions.

To confirm the participation of oxide ions in the charge compensation reaction, RIXS measurements were performed. RIXS spectra collected at the O K-edge represent the photon emissions accompanying the transition of an electron from the valence band to a core hole that has been created through the excitation of an electron to the conduction band. This technique therefore directly probes the states in the valence band. The RIXS of $\mathrm{O}$ K-edge shown in Figure 3d were generated by excitation of the electron to $531.5 \mathrm{eV}$ which is predominately where changes in the density of hole states are seen in the O K-edge XAS. On charging the material, a new feature is observed (indicated by an arrow) which is similar to previous observations for oxygen redox materials and is identical to that seen for NMMO. This has been recognized as a signature for $\mathrm{O}$ redox. ${ }^{5,27,28}$ These new electronic states that are created on charge clearly disappear on discharge, indicating the reversible nature of formation/loss of these states.

These evolving spectral features taken in combination with the O XAS and absence of change in Mn-oxidation state beyond $\mathrm{Mn}^{4+}$ confirm that $\sim 0.53$ mol of charge compensation
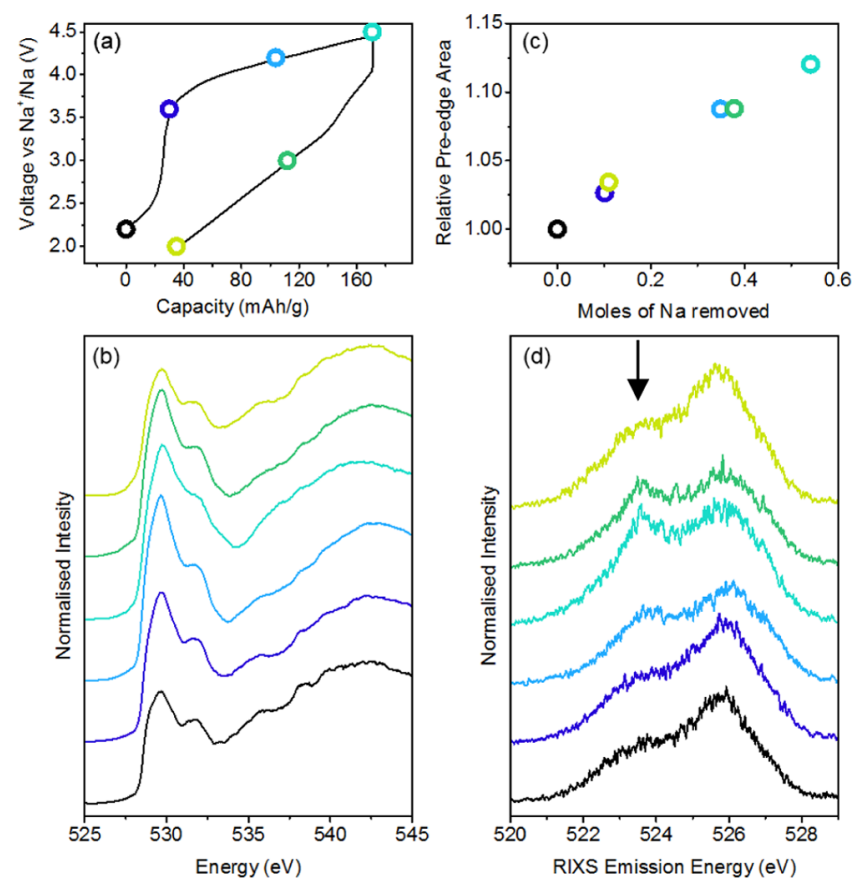

Figure 3. (a) Load curve for NLMO at $10 \mathrm{~mA} \mathrm{~g}^{-1}$ with colored points highlighting states of charge chosen for ex situ analysis, (b) O K-edge spectra collected at different states of charge in total fluorescence yield mode, (c) variation of the integrated pre-edge area in the low-energy region (below $533 \mathrm{eV}$ ) of the $\mathrm{O}$ K-edge showing a corresponding increase and decrease in hole states, and (d) RIXS on the O K-edge of NLMO with an excitation energy of $531.5 \mathrm{eV}$ shows the growth and diminution of a peak at an emission energy of $523.5 \mathrm{eV}$ on charge and discharge respectively (indicated by an arrow). Data were collected at the Swiss Light Source.

during cell charging is accounted for by creation of localized electron-hole states with mainly $\mathrm{O} 2 \mathrm{p}$ character. Comparing this with NMMO, for which $\sim 0.53 \mathrm{~mol}$ of electrons are removed overall up to the same cut off voltage of $4.5 \mathrm{~V}, \sim 0.4$ mol of which are removed from the oxide ions per formula unit (there being two $\mathrm{O}^{2-}$ p.f.u.), we observe $0.13 \mathrm{~mol}$ more in NLMO. This corresponds to a new average oxygen oxidation state of -1.74 for NLMO and -1.8 for NMMO.

2.4. Oxygen Loss. Most $O$ redox cathodes lose oxygen from the lattice during the first charge. ${ }^{5-8,12,19,20}$ We recently showed that, for NMMO, only $\mathrm{CO}_{2}$ originating from electrolyte oxidation and trace residual carbonates was released, despite a significant degree of $\mathrm{O}$ redox capacity and crucially with no loss of lattice O. We related this interesting result to the retention of $\mathrm{Mg}$ in the structure prompting us to conduct a thorough study on what structural conditions govern $\mathrm{O}$ release, specifically, how $\mathrm{O}$ loss is triggered by the movement of the TM layer substituent.

To investigate if $\mathrm{O}$ loss is observed in NLMO, where $\mathrm{Mg}$ is substituted for $\mathrm{Li}$ (which we expected to be more mobile), we conducted operando electrochemical mass spectrometry (OEMS) on NLMO under identical conditions to our previous study of NMMO. ${ }^{18}$ Because $\mathrm{Na}$ materials form carbonate species more readily than $\mathrm{Li}$ materials and as these can release $\mathrm{CO}_{2}$ during cell charging, we employed the same postsynthesis heat treatment under argon as had been used for NMMO to eliminate these impurities (details in Supporting Information). The absence of carbonates was confirmed by thermogravimetric analysis/mass spectrometry (TGA-MS, Figure S8). 

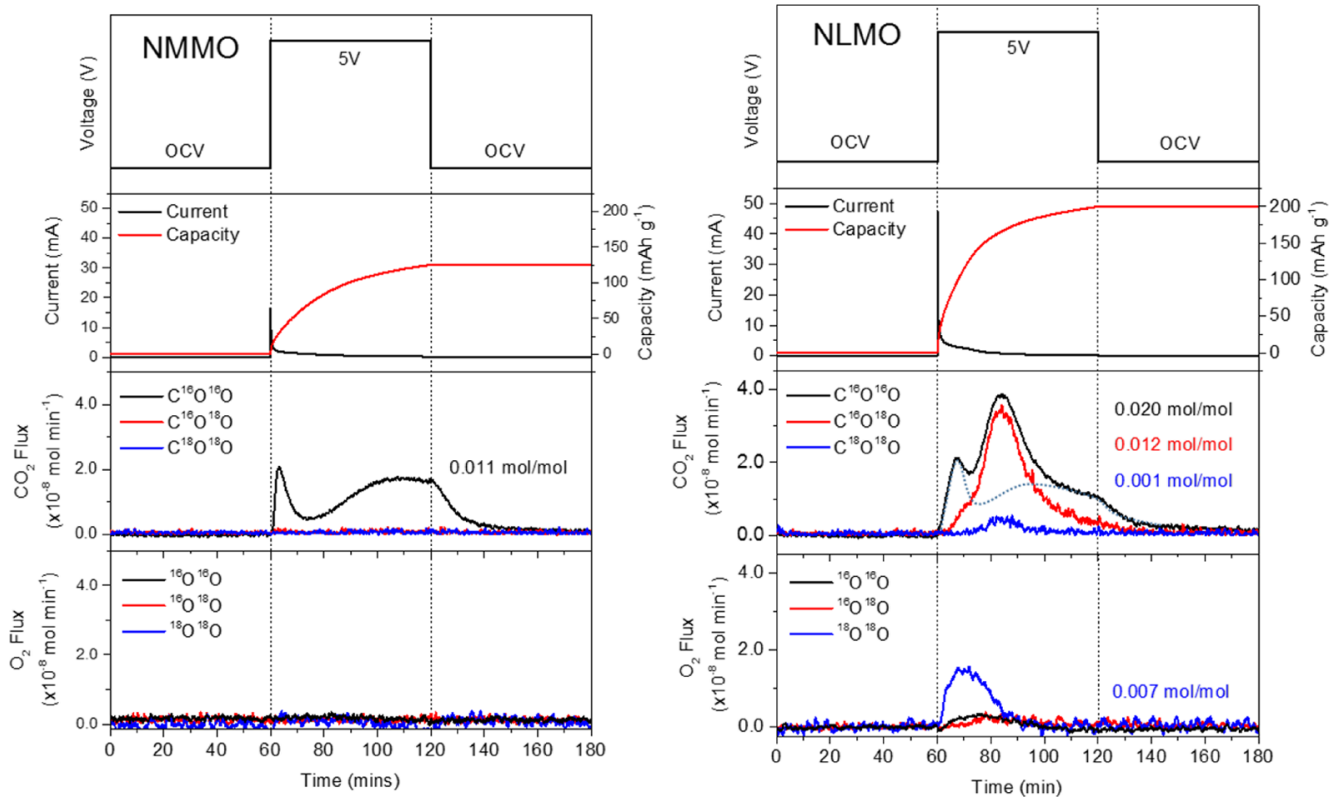

Figure 4. OEMS of ${ }^{18} \mathrm{O}$-labeled NMMO (left) versus NLMO (right) subjected to a potential step of $5 \mathrm{~V}$ for a period of $1 \mathrm{~h}$. The top panel shows the potential profile, the middle panel shows the current and capacity response and the bottom panel shows the traces from operando mass spectrometry. The dotted line on the $\mathrm{CO}_{2}$ trace for NLMO highlights the background gas release from trace carbonates and electrolyte oxidation as seen for NMMO. The NLMO capacity at $5 \mathrm{~V}$ is similar, $\sim 25 \mathrm{~mA} \mathrm{~h} \mathrm{~g}{ }^{-1}$ higher, than at constant current charging to $4.5 \mathrm{~V}$ in Figure 2 .

Considering the trace amount of $\mathrm{CO}_{2}$ detected by the TGAMS, as well as the sensitivity limits of this instrument, we are confident that no more than 0.1 wt $\%$ of $\mathrm{Na}_{2} \mathrm{CO}_{3}$ or $\mathrm{Li}_{2} \mathrm{CO}_{3}$ can remain present on the sample after our heat treatment step which would correspond to no more than $0.001 \mathrm{~mol}$ of $\mathrm{CO}_{2}$ per mole of NLMO. As can be seen in Figure S9, charging to the same potential (i.e., $4.5 \mathrm{~V}$ ) as NMMO resulted in no direct loss of $\mathrm{O}_{2}$ and a comparable quantity of $\mathrm{CO}_{2}$ to that of NMMO, relative to the quantity of active mass (Table S2). This confirms that charge compensation in NLMO occurs by $\mathrm{Mn}$ and $\mathrm{O}$ redox and that $\mathrm{O}$ loss is negligible in alignment with our observations for NMMO.

Other $\mathrm{O}$ redox compounds with $\mathrm{Li}$ in the TM layers, such as $\mathrm{Li}\left[\mathrm{Li}_{0.2} \mathrm{Ni}_{0.2} \mathrm{Mn}_{0.6}\right] \mathrm{O}_{2}$ and $\mathrm{Li}\left[\mathrm{Li}_{0.2} \mathrm{Ni}_{0.13} \mathrm{Co}_{0.13} \mathrm{Mn}_{0.54}\right] \mathrm{O}_{2}$ when charged to comparable voltages $\left(\sim 4.8 \mathrm{~V} \mathrm{vs} \mathrm{Li}^{+} / \mathrm{Li}\right.$ which is 4.5 $\mathrm{V}$ vs $\mathrm{Na}^{+} / \mathrm{Na}$ ) resulting in similar degrees of O-oxidation, show $\mathrm{O}$ loss. Therefore, at first sight, the absence of $\mathrm{O}$ loss in NLMO is somewhat surprising. In the case of these Li-rich Liion compounds, $\mathrm{Li}$ is extracted from the TM and alkali metal layers on charging such that, at the end of charge, the average coordination number around $\mathrm{O}$ falls below 3 (i.e., from 6, $\mathrm{Li}_{4} \mathrm{TM}_{2}$, to 2, $\square_{4} \mathrm{TM}_{2}$ ). However, for NLMO, insufficient alkali ions are removed from the structure to give rise to the same conditions (only $0.62 \mathrm{AM}$ ions are removed, which is lower than the 0.78 threshold necessary to form $\square_{4} \mathrm{TM}_{2}$ ).

To investigate whether $\mathrm{O}$ loss could be triggered in NMMO or NLMO by driving them to even higher degrees of alkali ion depletion, we conducted new OEMS experiments, this time subjecting each electrode material to a $5 \mathrm{~V}$ potential step. Because the potential at an intercalation electrode corresponds directly to the composition and hence alkali metal content just inside the surface, application of a $5 \mathrm{~V}$ hold drives the near surface of the electrode to a more alkali metal-depleted composition than the bulk almost immediately. In this way, we charge the electrode while avoiding spending prolonged times at high voltage thus avoiding significant electrolyte breakdown.
Nonetheless, under these highly oxidizing conditions direct electrolyte oxidation could occur. Therefore to decouple any gases evolved as side products of electrolyte oxidation from any $\mathrm{O}$ loss from the electrodes, we labeled each electrode material with ${ }^{18} \mathrm{O}$.

The results of these OEMS experiment are presented in Figure 4. On subjecting the ${ }^{18} \mathrm{O}$-labeled NMMO cathode to the potentiostatic charging conditions, we observed no evidence of ${ }^{18} \mathrm{O}$-labeled gases evolved. Instead only a small amount of unlabeled $\mathrm{CO}_{2}$ is released $(0.011 \mathrm{~mol}$ per mole of NMMO vs $0.44 \mathrm{~mol}$ of electrons passed). Because this gas does not contain ${ }^{18} \mathrm{O}$ it must originate from the electrolyte indicating some electrolyte oxidation at these high potentials. However, ICP measurements conducted post mortem on the electrode (Table S3) show a good agreement between the expected and measured AM content showing that electrolyte oxidation has a negligible influence on the electrochemistry.

In stark contrast to this result, when NLMO is subjected to the same $5 \mathrm{~V}$ potential step, we observed significant amounts of ${ }^{18} \mathrm{O}$-labeled $\mathrm{CO}_{2}$ (Figure 4) in addition to the background $\mathrm{CO}_{2}$ release from electrolyte oxidation as seen also for NMMO (outlined with a dotted line). Because only the cathode material is ${ }^{18} \mathrm{O}$-labeled, this $\mathrm{O}$ must originate from the lattice. The additional $\mathrm{CO}_{2}$ for NLMO is released as a consequence of reaction of oxidized oxygen with the carbonate electrolyte solvent molecules giving rise to both labeled and unlabeled $\mathrm{CO}_{2}$. These reactions have been investigated in detail by Gasteiger and co-workers and likely arise from release of reactive singlet $\mathrm{O}_{2}$ species from the cathode. ${ }^{29,30}$ Furthermore, there is direct loss of $\mathrm{O}_{2}$ gas, which is predominantly twicelabeled $\left({ }^{18} \mathrm{O}^{18} \mathrm{O}\right)$, indicating that it originates almost exclusively from the lattice and that the material is ${ }^{18} \mathrm{O}$-rich. Overall, a total of $\sim 0.03 \mathrm{~mol}$ of $\mathrm{O}$ per mole of NLMO is extracted directly from the lattice at $5 \mathrm{~V}$, but none from NMMO. 
In Li-rich compounds, oxygen loss has been shown to occur predominantly at the surface of the electrode particles resulting in the formation of densified spinel and rocksalt. ${ }^{4,31-35}$ Interested in understanding the spatial origin of the $\mathrm{O}$ loss from NLMO, we conducted elemental mapping using electron energy loss spectroscopy (EELS) of the Mn L- and O K-edges on electrode particles recovered after charging to $4.5 \mathrm{~V}$ (no $\mathrm{O}$ loss detected by OEMS) and compared this with an electrode sample charged at $5 \mathrm{~V}$ (O loss). The results in Figure 5 show

\section{(a) NLMO 4.5V}

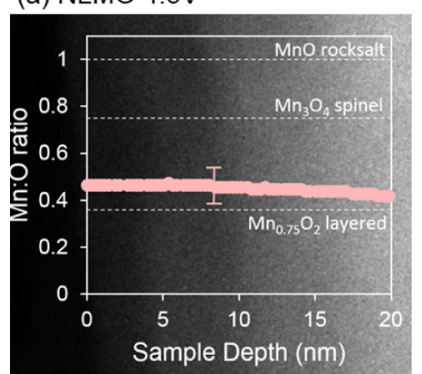

(b) NLMO 5.0V

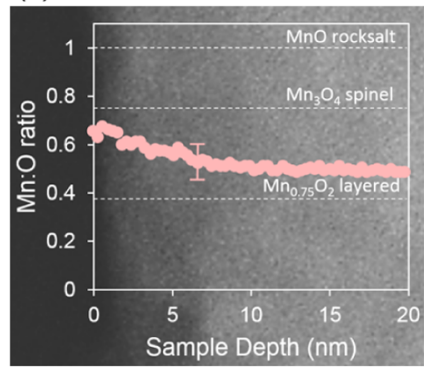

Figure 5. EELS line scans of NLMO electrodes charged (a) galvanostatically to $4.5 \mathrm{~V}$ and (b) potentiostatically at $5 \mathrm{~V}$. Plots show the $\mathrm{Mn} / \mathrm{O}$ ratio as a function of sample depth. Dashed lines represent $\mathrm{Mn} / \mathrm{O}$ ratios of possible surface layer phases.

clear evidence of a manganese-rich composition forming in the electrode where O loss is observed from OEMS but only in the near surface region $(\sim 10 \mathrm{~nm})$ consistent with a densification mechanism. Calculating the amount of $\mathrm{O}$ loss that would be implied by the composition change in the $10 \mathrm{~nm}$ shell (assuming $1 \mu \mathrm{m}$ spherical particles) reveals a close match with the moles of $\mathrm{O}$ detected from OEMS ( 0.03 vs $0.028 \mathrm{~mol}$ of $\mathrm{O}$ lost from NLMO) indicating that $\mathrm{O}$ is only lost from the surface.

2.5. Li Mobility. To understand further the role of $\mathrm{Li}$ in triggering $\mathrm{O}$ loss in $\mathrm{NLMO}$, we carried out ${ }^{6} \mathrm{Li}$ solid-state NMR on ${ }^{6} \mathrm{Li}$-enriched cathodes. Figure 6 compares the sample-weight normalized spectra between pristine NLMO; NLMO after galvanostatic charging to $4.5 \mathrm{~V}$; and NLMO after potentiostatic charging at $5 \mathrm{~V}$.

As can be seen from the deconvolved spectra, the lithium environment(s) $\mathbf{L i}_{\mathrm{TM}}$ (purple) which is centered at $1850 \mathrm{ppm}$ reduces in intensity upon charging and a new environment(s) $\mathrm{Li}_{\mathrm{AM}}$ (green) is formed centered around $607 \mathrm{ppm}$ (see Figure 6). Following Grey, ${ }^{36}$ we interpret this significant change in NMR shift as a result of Li moving out of the TM layer, $\mathbf{L} \mathbf{i}_{\mathrm{TM}}$, and into the $\mathrm{Na}$ layer, $\mathbf{L i}_{\mathrm{AM}}$. The broad shift value of $607 \mathrm{ppm}$ indicates the $\mathbf{L i}_{\mathrm{AM}}$ is in $\mathrm{O}_{\mathrm{h}}$ sites in O-type stacking faults in the $\mathrm{Na}$ layer rather than in trigonal prismatic sites in P-stacked layers as recently shown by Clément et al. in other $\mathrm{Na}$ cathodes. $^{36}$

To probe whether $\mathrm{Li}$ is lost from the structure altogether, we conducted ICP, Table S3. At $4.5 \mathrm{~V}$, the results show that only $\mathrm{Na}^{+}$is removed from the structure and $\mathrm{Li}$ remains. Given the ${ }^{6} \mathrm{Li}$ NMR studies which demonstrate that, although no $\mathrm{Li}$ is extracted it is displaced from the TM layers to alkali metal layers, we see that the formation of vacancies in the TM layers is not, in itself, sufficient to trigger $\mathrm{O}$ loss. In contrast, the ICP results for the NLMO sample charged at $5 \mathrm{~V}$ show a definite decrease in the overall $\mathrm{Li}$ content as a result of the highly oxidizing charging conditions ( 0.16 vs 0.24 at $4.5 \mathrm{~V}$ ) along with $\mathrm{Na}^{+}$removal. Under these conditions $\mathrm{O}$ loss is triggered
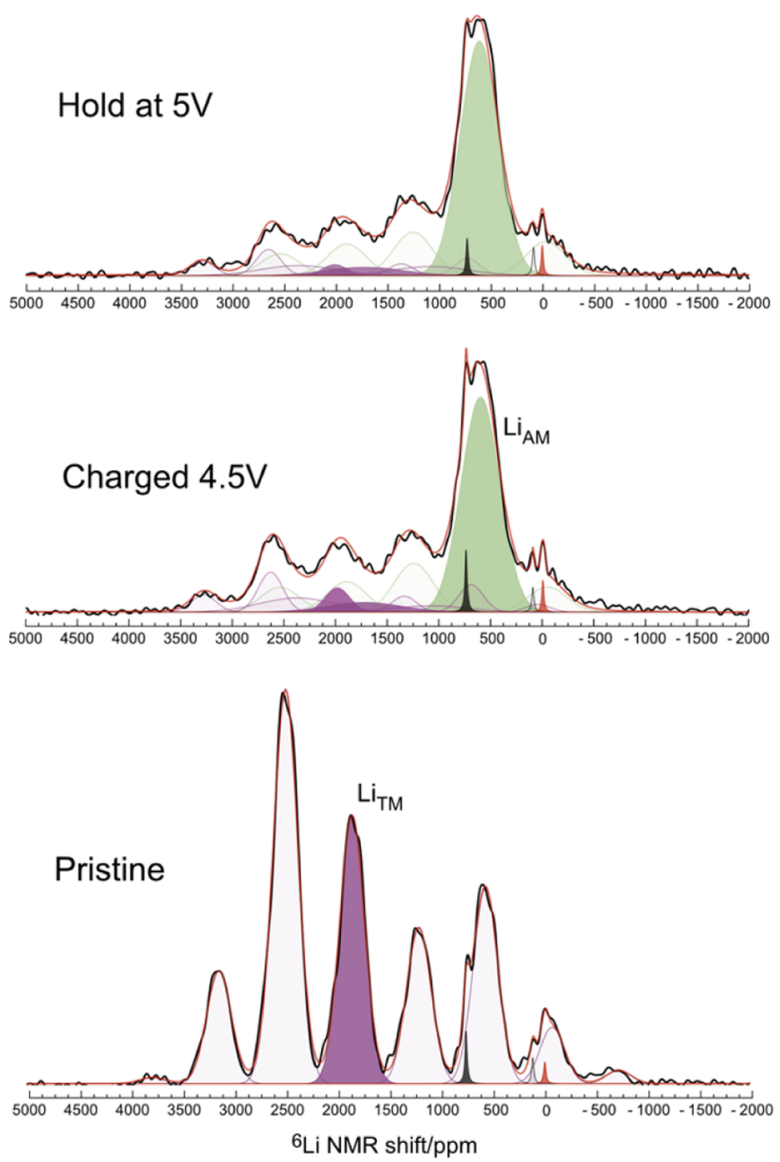

Figure 6. ${ }^{6} \mathrm{Li}$ MAS NMR spectra (black lines) of NLMO pristine (bottom), charged to $4.5 \mathrm{~V}$ (middle) and hold at $5 \mathrm{~V}$ (top). The spectra are broken down into color-coded lithium sites whose isotropic shifts are shaded. The rest of the spectra are spinning sidebands. The red lines are the overall fitting to the spectra. The shift(s) in pristine sample (labeled $\mathbf{L i}_{\mathrm{TM}}$ ) should be viewed as an ensemble of $\mathrm{Li}$ in TM layer environments centered around $1850 \mathrm{ppm}$ (because of chemical shift anisotropy, the envelope of spinning sidebands is not symmetric around the isotropic line). The charged samples have one major new shift (labeled $\mathrm{Li}_{\mathrm{AM}}$ ), which again is an ensemble of shifts centered around $607 \mathrm{ppm}$. Also, in the charged samples, the $\mathbf{L i}_{\mathrm{TM}}$ shift has to be fitted with at least two Gaussian lines to capture the more disordered $\mathbf{L i}_{\mathrm{TM}}$ environments after charge. There are two identified impurity phases in all three spectra: $\mathrm{Li}_{2} \mathrm{MnO}_{3}$ phase as shown by the isotropic shift of its $\mathrm{Li}$ layer around $730 \mathrm{ppm}$ (black shaded, and its sideband at $100 \mathrm{ppm}$ ) and a diamagnetic phase at $0 \mathrm{ppm}$ (red shaded).

from the surface of NLMO. To investigate whether $\mathrm{Li}$ is being depleted from the same surface region as the O loss, energytuned depth profiling X-ray photoelectron spectroscopy (XPS) was conducted. As can be seen in Figure S10, there is a noticeable reduction in the $\mathrm{Li}(1 \mathrm{~s})$ peak intensity at different photon energies of 0.25 and $2.35 \mathrm{keV}$ corresponding to $\mathrm{Li}$ located in the first $1-2$ and $10 \mathrm{~nm}$ depths, respectively, in the material. From this, we conclude that $\mathrm{O}$ loss is correlated with removal of enough alkali metal ions around $\mathrm{O}$ to leave them underbonded (i.e., <3). This only occurs when the TM substituent is removed from the electrode explaining why no $\mathrm{O}$ loss is observed for $\mathrm{NMMO}$, where $\mathrm{Mg}$ is retained, even under very oxidizing conditions. 

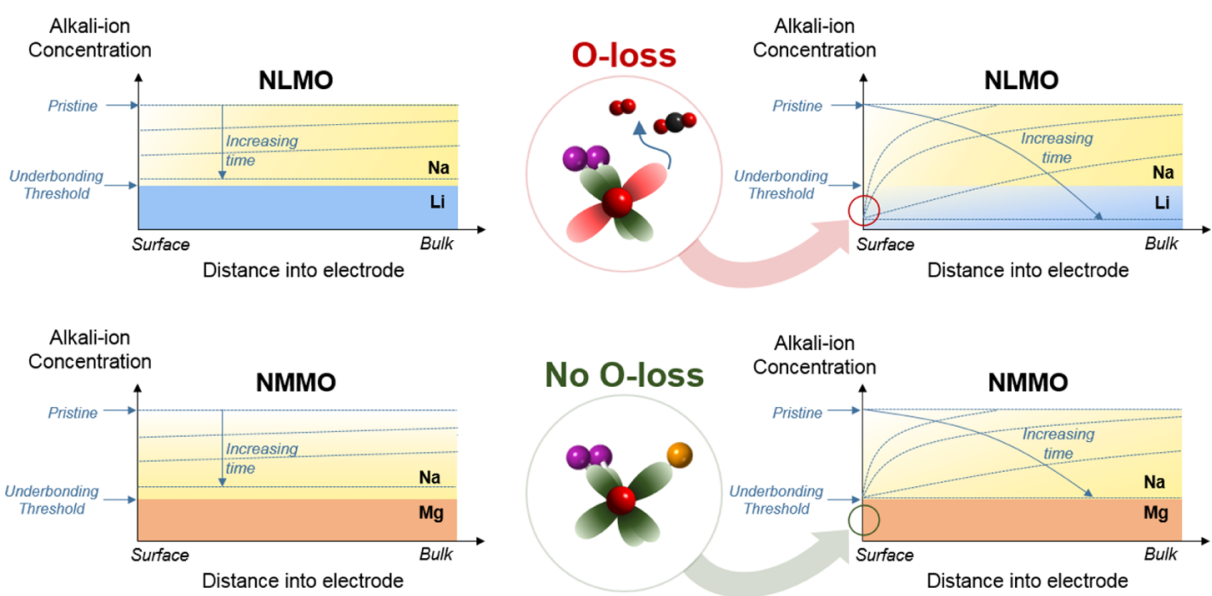

Figure 7. Schematic representation of the concentration profiles of alkali ions $\mathrm{Li}, \mathrm{Na}$, and $\mathrm{Mg}$ within NLMO and NMMO electrode particles as a function of charging time under (a) $4.5 \mathrm{~V}$ galvanostatic and (b) $5.0 \mathrm{~V}$ potentiostatic continuous charging conditions. Structural schematics illustrate the coordination environments around oxidized $\mathrm{O}$ atoms in the near surface region. Complete depletion of four alkali ions from the coordination sphere of $\mathrm{O}$ leaves it severely underbonded and liable to $\mathrm{O}$ loss' this occurs only under highly oxidizing charging conditions in NLMO.

\section{DISCUSSION}

While oxygen loss from materials exhibiting oxygen redox has been known for a long time, efforts to uncover the underlying structural and chemical triggers remain inconclusive. It might be considered that the degree of oxide ion oxidation would control the stability of $\mathrm{O}$ and hence its loss from the lattice. However, our studies here on $\mathrm{Na}_{0.78} \mathrm{Li}_{0.25} \mathrm{Mn}_{0.75} \mathrm{O}_{2}$, where no $\mathrm{O}$ loss is observed despite $0.53 \mathrm{~mol}$ of charge removed being associated with oxidation of the oxide ion, similar to analogous compounds with Li-substituted TM layers like Li$\left[\mathrm{Li}_{0.2} \mathrm{Ni}_{0.2} \mathrm{Mn}_{0.6}\right] \mathrm{O}_{2}\left(0.56 e^{-}\right)$and $\mathrm{Li}\left[\mathrm{Li}_{0.2} \mathrm{Ni}_{0.13} \mathrm{Co}_{0.13} \mathrm{Mn}_{0.54}\right] \mathrm{O}_{2}$ $\left(0.6 e^{-}\right)$, where $\mathrm{O}$ loss is observed, demonstrate that this is not the case. On charging $\mathrm{Li}\left[\mathrm{Li}_{0.2} \mathrm{Ni}_{0.2} \mathrm{Mn}_{0.6}\right] \mathrm{O}_{2}$ and $\mathrm{Li}-$ $\left[\mathrm{Li}_{0.2} \mathrm{Ni}_{0.13} \mathrm{Co}_{0.13} \mathrm{Mn}_{0.54}\right] \mathrm{O}_{2}, \mathrm{Li}^{+}$ions are lost from the $\mathrm{TM}$ layers, creating vacancies that could play a role in triggering $\mathrm{O}$ loss. Charging $\mathrm{P} 2-\mathrm{Na}_{0.78} \mathrm{Li}_{0.25} \mathrm{Mn}_{0.75} \mathrm{O}_{2}$ to the same degree up to $4.5 \mathrm{~V}$ also results in loss of $\mathrm{Li}^{+}$from the $\mathrm{TM}$ layer and the creation of vacancies but without $\mathrm{O}$ loss. These results demonstrate that $\mathrm{O}$ loss is not triggered by vacancies in the TM layers.

Instead, $\mathrm{O}$ loss is triggered by driving the electrode to high degrees of alkali-ion deficiency such that the local coordination around $\mathrm{O}$ is reduced below 3 , that is, $\left(\square_{4} \mathrm{TM}_{2}\right)$. This occurs in $\mathrm{Na}_{0.78} \mathrm{Li}_{0.25} \mathrm{Mn}_{0.75} \mathrm{O}_{2}$ on charging at $5 \mathrm{~V}$. Under these highly oxidizing conditions, both $\mathrm{Li}^{+}$and $\mathrm{Na}^{+}$are removed from the structure leaving unstable, underbonded $\mathrm{O}$ that is coordinated by only $2 \mathrm{Mn}$ (Figure 7 ). In this case, O loss is observed originating exclusively from the surface of the electrode, leaving behind a TM densified shell (higher TM/O ratio) potentially bearing structural resemblance to that of Li-rich materials. ${ }^{4,31-35}$ The lack of $\mathrm{O}$ loss from $\mathrm{Na}_{0.67} \mathrm{Mg}_{0.28} \mathrm{Mn}_{0.72} \mathrm{O}_{2}$ even at $5 \mathrm{~V}$ indicates that $\mathrm{O}$ is not underbonded even at the surface. In this case, with no $\mathrm{O}$ or $\mathrm{Mg}$ loss, densification is not possible and $\mathrm{O}$ remains coordinated by three cations, $2 \mathrm{Mn}^{4+}$ and $1 \mathrm{Mg}^{2+}$ due to the much lower mobility of $\mathrm{Mg}^{2+}$ compared with $\mathrm{Li}^{+}$, as indicated by ICP (Tables S3 and S4). Therein we demonstrated that $\mathrm{O}$ loss is not an inevitable consequence of O-oxidation or charging to high voltages $\left(4.5 \mathrm{~V} \mathrm{vs} \mathrm{Na}^{+} / \mathrm{Na}, 4.8\right.$ $\mathrm{Vvs} \mathrm{Li}^{+} / \mathrm{Li}$ ) but is instead controlled by depletion of alkali ions from the local coordination environment.

\section{CONCLUSIONS}

$\mathrm{O}$ loss is an undesirable characteristic of high-capacity $\mathrm{O}$ redox cathode materials. Understanding what factors trigger or suppress $\mathrm{O}$ loss is an important step toward realizing the potential of these materials. In this work we have compared directly two analogous $\mathrm{O}$ redox layered cathode materials P2$\mathrm{Na}_{x}\left[\mathrm{~A}_{y} \mathrm{Mn}_{1-y}\right] \mathrm{O}_{2}$ (where $\mathrm{A}=\mathrm{Li}$ or $\mathrm{Mg}$ ), one with more mobile ions in the TM layers, $\mathrm{P} 2-\mathrm{Na}_{0.78}\left[\mathrm{Li}_{0.25} \mathrm{Mn}_{0.75}\right] \mathrm{O}_{2}$, and one without, $\mathrm{P} 2-\mathrm{Na}_{0.67}\left[\mathrm{Mg}_{0.28} \mathrm{Mn}_{0.72}\right] \mathrm{O}_{2}$, and scrutinized their $\mathrm{O}$ loss behaviors. We have shown that $\mathrm{O}$ loss is not an inevitable consequence of $\mathrm{O}$ redox nor of migration of excess alkali-ions out of the TM-layer. Instead, O loss is triggered when the structure becomes significantly depleted of alkali ions leaving oxidized $\mathrm{O}$ severely underbonded (fewer than 3 coordinating cations). Such conditions can be imposed upon P2$\mathrm{Na}_{0.78} \mathrm{Li}_{0.25} \mathrm{Mn}_{0.75} \mathrm{O}_{2}$ by application of a high potential, which drives alkali metal depletion promoting underbonding and $\mathrm{O}$ loss from the surface of the electrode particles. This results in a TM densified surface layer as observed in Li-rich cathode materials. Our findings suggest that strategies to stabilize locally underbonded oxidized $\mathrm{O}$ species in near surface regions must be employed to avoid triggering O loss. Only then can the capacity benefits of alkali-rich compositions be fully realized.

\section{ASSOCIATED CONTENT}

S Supporting Information

The Supporting Information is available free of charge on the ACS Publications website at DOI: 10.1021/acs.chemmater.9b00227.

Neutron diffraction data, further electron microscopy imaging, operando X-ray diffraction, XANES, operando electrochemical mass spectroscopy data, TGA-MS, ICP-OES elemental analysis, and XPS (PDF)

\section{AUTHOR INFORMATION}

\section{Corresponding Author}

*E-mail: peter.bruce@materials.ox.ac.uk. 


\section{ORCID}

Robert A. House: 0000-0002-7415-477X

Liyu Jin: 0000-0003-1003-0855

Juan G. Lozano: 0000-0003-2900-3902

James W. Somerville: 0000-0002-7848-2607

Alan V. Chadwick: 0000-0002-6485-9207

Peter G. Bruce: 0000-0001-6748-3084

\section{Present Address}

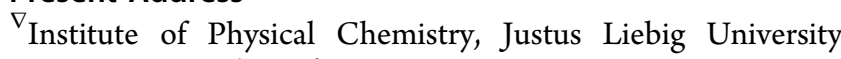
Giessen, Heinrich-Buff-Ring 17, Room B48, 35392 Giessen, GERMANY.

\section{Author Contributions}

R.A.H. and U.M. contributed equally. R.A.H., U.M., and M.R.R. contributed to all aspects of the research. L.J. and N.H.R. collected, processed, and interpreted the NMR data. J.G.L. collected, processed, and interpreted the ADF-STEM images. J.W.S., L.C.D., F.M., D.E.M., and T.S. contributed toward the measurements of the SXAS and RIXS spectroscopy. A.V.C., S.R., and D.M.P. contributed to the data collection and analysis of hard XAS measurements. A.J.N. collected the XPS data and contributed to the data analysis. P.G.B., R.A.H., U.M., L.J., and M.R.R. interpreted the data. The project was supervised by P.G.B.

\section{Funding}

P.G.B. is indebted to the Engineering and Physical Sciences Research Council (EPSRC), including the SUPERGEN Energy Storage Hub [EP/L019469/1], Enabling Next Generation Lithium Batteries [EP/M009521/1], Henry Royce Institute for capital equipment [EP/R010145/1] and the Faraday Institution All-Solid-State Batteries with $\mathrm{Li}$ and $\mathrm{Na}$ Anodes [FIRG007, FIRG008] for the financial support. The support from the EPSRC EP/K040375/1 ("South of England Analytical Electron Microscope") is also gratefully acknowledged.

Notes

The authors declare no competing financial interest.

\section{ACKNOWLEDGMENTS}

The authors thank N. Kumar, Max Planck Institute of Chemical Physics, for help with magnetic measurements. Synchrotron soft X-ray radiation experiments were performed at the ADRESS beam-line of the Swiss Light Source at the Paul Scherrer Institute, Switzerland. We acknowledge technical and experimental support at the ADRESS beamline by L. Nue and M. Dantz. Part of this research was funded by the Swiss National Science Foundation through the NCCR MARVEL. We thank the diamond light source for the award of beam time for the hard X-ray experiments on beamline B18 as part of the Energy Materials Block Allocation Group SP14239. The authors are also grateful to G. Cibin for contributing to the collection of hard XAS data. This work was carried out with the support of the diamond light source, instrument I09 (proposal SI20870).

\section{REFERENCES}

(1) Whittingham, M. S. Lithium Batteries and Cathode Materials. Chem. Rev. 2004, 104, 4271-4302.

(2) Seo, D.-H.; Lee, J.; Urban, A.; Malik, R.; Kang, S.; Ceder, G. The Structural and Chemical Origin of the Oxygen Redox Activity in Layered and Cation-Disordered Li-Excess Cathode Materials. Nat. Chem. 2016, 8, 692-697.
(3) Kim, J.-S.; Johnson, C. S.; Vaughey, J. T.; Thackeray, M. M.; Hackney, S. a.; Yoon, W.; Grey, C. P. Electrochemical and Structural Properties of $\mathrm{XLi}_{2} \mathrm{M}^{\prime} \mathrm{O}_{3} \cdot(1-\mathrm{x}) \mathrm{LiMn}_{0.5} \mathrm{Ni}_{0.5} \mathrm{O}_{2}$ Electrodes for Lithium Batteries $\left(\mathrm{M}^{\mathrm{r}}=\mathrm{Ti}, \mathrm{Mn}, \mathrm{Zr} ; 0 \leq \mathrm{x} \leq 0.3\right)$. Chem. Mater. 2004, 16, 1996-2006.

(4) Koga, H.; Croguennec, L.; Ménétrier, M.; Mannessiez, P.; Weill, F.; Delmas, C. Different Oxygen Redox Participation for Bulk and Surface: A Possible Global Explanation for the Cycling Mechanism of Li1.20Mn0.54Co0.13Ni0.13O2. J. Power Sources 2013, 236, 250-258.

(5) Luo, K.; Roberts, M. R.; Hao, R.; Guerrini, N.; Pickup, D. M.; Liu, Y.-S.; Edström, K.; Guo, J.; Chadwick, A. V.; Duda, L. C.; et al. Charge-Compensation in 3d-Transition-Metal-Oxide Intercalation Cathodes through the Generation of Localized Electron Holes on Oxygen. Nat. Chem. 2016, 8, 684-691.

(6) Perez, A. J.; Batuk, D.; Saubanère, M.; Rousse, G.; Foix, D.; McCalla, E.; Berg, E. J.; Dugas, R.; H. W. van den Bos, K.; Doublet, M.-L.; et al. Strong Oxygen Participation in the Redox Governing the Structural and Electrochemical Properties of Na-Rich Layered Oxide $\mathrm{Na}_{2} \mathrm{IrO}_{3}$. Chem. Mater. 2016, 28, 8278-8288.

(7) McCalla, E.; Abakumov, A. M.; Saubanere, M.; Foix, D.; Berg, E. J.; Rousse, G.; Doublet, M.-L.; Gonbeau, D.; Novak, P.; Van Tendeloo, G.; et al. Visualization of O-O Peroxo-like Dimers in HighCapacity Layered Oxides for Li-Ion Batteries. Science 2015, 350, $1516-1521$.

(8) Sathiya, M.; Rousse, G.; Ramesha, K.; Laisa, C. P.; Vezin, H.; Sougrati, M. T.; Doublet, M.-L.; Foix, D.; Gonbeau, D.; Walker, W.; et al. Reversible Anionic Redox Chemistry in High-Capacity LayeredOxide Electrodes. Nat. Mater. 2013, 12, 827-835.

(9) Lu, Z.; Dahn, J. R. Understanding the Anomalous Capacity of $\mathrm{Li} / \mathrm{Li}[\mathrm{Ni}[\operatorname{sub} \mathrm{x}] \mathrm{Li}[\operatorname{sub}(1 / 3-2 \mathrm{x} / 3)] \mathrm{Mn}[\operatorname{sub}(2 / 3-\mathrm{x} / 3)]] \mathrm{O}[\operatorname{sub} 2]$ Cells Using In Situ X-Ray Diffraction and Electrochemical Studies. J. Electrochem. Soc. 2002, 149, A815.

(10) Oishi, M.; Fujimoto, T.; Takanashi, Y.; Orikasa, Y.; Kawamura, A.; Ina, T.; Yamashige, H.; Takamatsu, D.; Sato, K.; Murayama, H.; et al. Charge Compensation Mechanisms in Li1.16Ni0.15Co0.19Mn0.50O2 Positive Electrode Material for Li-Ion Batteries Analyzed by a Combination of Hard and Soft X-Ray Absorption near Edge Structure. J. Power Sources 2013, 222, 45-51.

(11) Yabuuchi, N.; Yoshii, K.; Myung, S.-T.; Nakai, I.; Komaba, S. Detailed Studies of a High-Capacity Electrode Material for Rechargeable Batteries, Li2MnO3-LiCo1/3Ni1/3Mn1/3O2. J. Am. Chem. Soc. 2011, 133, 4404-4419.

(12) Luo, K.; Roberts, M. R.; Guerrini, N.; Tapia-Ruiz, N.; Hao, R.; Massel, F.; Pickup, D. M.; Ramos, S.; Liu, Y.-S.; Guo, J.; et al. Anion Redox Chemistry in the Cobalt Free 3d Transition Metal Oxide Intercalation Electrode $\mathrm{Li}\left[\mathrm{Li}_{0.2} \mathrm{Ni}_{0.2} \mathrm{Mn}_{0.6}\right] \mathrm{O}_{2}$. J. Am. Chem. Soc. 2016, 138, 11211-11218.

(13) Pearce, P. E.; Perez, A. J.; Rousse, G.; Saubanère, M.; Batuk, D.; Foix, D.; McCalla, E.; Abakumov, A. M.; Van Tendeloo, G.; Doublet, M.-L.; et al. Evidence for anionic redox activity in a tridimensionalordered Li-rich positive electrode $\beta$-Li2IrO3. Nat. Mater. 2017, 16, $580-586$.

(14) Sathiya, M.; Ramesha, K.; Rousse, G.; Foix, D.; Gonbeau, D.; Prakash, A. S.; Doublet, M. L.; Hemalatha, K.; Tarascon, J.-M. High Performance Li2Ru1-yMnyO3 $(0.2 \leq \mathrm{y} \leq 0.8)$ Cathode Materials for Rechargeable Lithium-Ion Batteries: Their Understanding. Chem. Mater. 2013, 25, 1121-1131.

(15) Tamaru, M.; Wang, X.; Okubo, M.; Yamada, A. Layered $\mathrm{Na} 2 \mathrm{RuO} 3$ as a Cathode Material for Na-Ion Batteries. Electrochem. Commun. 2013, 33, 23-26.

(16) Rozier, P.; Sathiya, M.; Paulraj, A.-R.; Foix, D.; Desaunay, T.; Taberna, P.-L.; Simon, P.; Tarascon, J.-M. Anionic Redox Chemistry in Na-Rich Na2Ru1-ySnyO3 Positive Electrode Material for Na-Ion Batteries. Electrochem. Commun. 2015, 53, 29-32.

(17) Mortemard de Boisse, B.; Liu, G.; Ma, J.; Nishimura, S.-I.; Chung, S.-C.; Kiuchi, H.; Harada, Y.; Kikkawa, J.; Kobayashi, Y.; Okubo, M.; et al. Intermediate Honeycomb Ordering to Trigger Oxygen Redox Chemistry in Layered Battery Electrode. Nat. Commun. 2016, 7, 11397. 
(18) Maitra, U.; House, R. A.; Somerville, J. W.; Tapia-Ruiz, N.; Lozano, J. G.; Guerrini, N.; Hao, R.; Luo, K.; Jin, L.; Pérez-Osorio, M. A.; et al. Oxygen Redox Chemistry without Excess Alkali-Metal Ions in $\mathrm{Na}_{2 / 3}\left[\mathrm{Mg}_{0.28} \mathrm{Mn}_{0.72}\right] \mathrm{O}_{2}$. Nat. Chem. 2018, 10, 288-295.

(19) Armstrong, A. R.; Holzapfel, M.; Novák, P.; Johnson, C. S.; Kang, S.-H.; Thackeray, M. M.; Bruce, P. G. Demonstrating Oxygen Loss and Associated Structural Reorganization in the Lithium Battery Cathode $\mathrm{Li}[\mathrm{Ni0}$.2Li0.2Mn0.6]O2. J. Am. Chem. Soc. 2006, 128, 8694-8698.

(20) Yu, D. Y. W.; Yanagida, K.; Kato, Y.; Nakamura, H. Electrochemical Activities in $\mathrm{Li}_{2} \mathrm{MnO}_{3}$. J. Electrochem. Soc. 2009, 156, A417.

(21) Yabuuchi, N.; Hara, R.; Kajiyama, M.; Kubota, K.; Ishigaki, T.; Hoshikawa, A.; Komaba, S. New O2/P2-Type Li-Excess Layered Manganese Oxides as Promising Multi-Functional Electrode Materials for Rechargeable Li/Na Batteries. Adv. Energy Mater. 2014, 4, 1301453.

(22) De La Llave, E.; Talaie, E.; Levi, E.; Nayak, P. K.; Dixit, M.; Rao, P. T.; Hartmann, P.; Chesneau, F.; Major, D. T.; Greenstein, M.; et al. Improving Energy Density and Structural Stability of Manganese Oxide Cathodes for Na-Ion Batteries by Structural Lithium Substitution. Chem. Mater. 2016, 28, 9064-9076.

(23) Du, K.; Zhu, J.; Hu, G.; Gao, H.; Li, Y.; Goodenough, J. B. Exploring Reversible Oxidation of Oxygen in a Manganese Oxide. Energy Environ. Sci. 2016, 9, 2575.

(24) Rong, X.; Liu, J.; Hu, E.; Liu, Y.; Wang, Y.; Wu, J.; Yu, X.; Page, K.; Hu, Y.-S.; Yang, W.; et al. Structure-Induced Reversible Anionic Redox Activity in Na Layered Oxide Cathode. Joule 2018, 2, 125140.

(25) Yabuuchi, N.; Hara, R.; Kubota, K.; Paulsen, J.; Kumakura, S.; Komaba, S. A New Electrode Material for Rechargeable Sodium Batteries: P2-Type $\mathrm{Na}_{2 / 3}\left[\mathrm{Mg}_{0.28} \mathrm{Mn}_{0.72}\right] \mathrm{O}_{2}$ with Anomalously High Reversible Capacity. J. Mater. Chem. A 2014, 2, 16851-16855.

(26) Delmas, C.; Fouassier, C.; Hagenmuller, P. Structural Classification and Properties of the Layered Oxides. Physica $B+C$ 1980, 99, 81-85.

(27) Gent, W. E.; Lim, K.; Liang, Y.; Li, Q.; Barnes, T.; Ahn, S. J.; Stone, K. H.; McIntire, M.; Hong, J.; Song, J. H.; et al. Coupling between Oxygen Redox and Cation Migration Explains Unusual Electrochemistry in Lithium-Rich Layered Oxides. Nat. Commun. 2017, 8, 2091.

(28) Xu, J.; Sun, M.; Qiao, R.; Renfrew, S. E.; Ma, L.; Wu, T.; Hwang, S.; Nordlund, D.; Su, D.; Amine, K.; et al. Elucidating Anionic Oxygen Activity in Lithium-Rich Layered Oxides. Nat. Commun. 2018, 9, 947.

(29) Wandt, J.; Freiberg, A. T. S.; Ogrodnik, A.; Gasteiger, H. A. Singlet Oxygen Evolution from Layered Transition Metal Oxide Cathode Materials and Its Implications for Lithium-Ion Batteries. Mater. Today 2018, 21, 825.

(30) Jung, R.; Metzger, M.; Maglia, F.; Stinner, C.; Gasteiger, H. A. Oxygen Release and Its Effect on the Cycling Stability of $\mathrm{LiNi}_{\mathrm{x}} \mathrm{Mn}_{\mathrm{y}} \mathrm{Co}_{\mathrm{z}} \mathrm{O}_{2}(\mathrm{NMC})$ Cathode Materials for Li-Ion Batteries. J. Electrochem. Soc. 2017, 164, A1361-A1377.

(31) Koga, H.; Croguennec, L.; Menetrier, M.; Douhil, K.; Belin, S.; Bourgeois, L.; Suard, E.; Weill, F.; Delmas, C. Reversible Oxygen Participation to the Redox Processes Revealed for $\mathrm{Li}_{1.20} \mathrm{Mn}_{0.54} \mathrm{Co}$ ${ }_{0.13} \mathrm{Ni}_{0.13} \mathrm{O}_{2}$. J. Electrochem. Soc. 2013, 160 (6), A786-A792.

(32) Tran, N.; Croguennec, L.; Ménétrier, M.; Weill, F.; Biensan, P.; Jordy, C.; Delmas, C. Mechanisms Associated with the "Plateau" Observed at High Voltage for the Overlithiated $\mathrm{Li}_{1.12}\left(\mathrm{Ni}_{0.425} \mathrm{Mn}_{0.425} \mathrm{Co}_{0.15}\right)_{0.88} \mathrm{O}_{2}$ System. Chem. Mater. 2008, 20, 4815-4825.

(33) Armstrong, A. R.; Holzapfel, M.; Novák, P.; Johnson, C. S.; Kang, S.-H.; Thackeray, M. M.; Bruce, P. G. Demonstrating Oxygen Loss and Associated Structural Reorganization in the Lithium Battery Cathode $\mathrm{Li}\left[\mathrm{Ni}_{0.2} \mathrm{Li}_{0.2} \mathrm{Mn}_{0.6}\right] \mathrm{O}_{2}$. J. Am. Chem. Soc. 2006, 128, 86948698.

(34) Weill, F.; Tran, N.; Martin, N.; Croguennec, L.; Delmas, C. Electron Diffraction Study of the Layered
$\mathrm{Li}_{\mathrm{y}}\left(\mathrm{Ni}_{0.425} \mathrm{Mn}_{0.425} \mathrm{Co}_{0.15}\right)_{0.88} \mathrm{O}_{2}$ Materials Reintercalated after Two Different States of Charge. Electrochem. Solid-State Lett. 2007, 10, A194.

(35) Yu, H.; So, Y.-G.; Ren, Y.; Wu, T.; Guo, G.; Xiao, R.; Lu, J.; Li, H.; Yang, Y.; Zhou, H.; et al. Temperature-Sensitive Structure Evolution of Lithium-Manganese-Rich Layered Oxides for LithiumIon Batteries. J. Am. Chem. Soc. 2018, 140, 15279-15289.

(36) Clément, R. J.; Xu, J.; Middlemiss, D. S.; Alvarado, J.; Ma, C.; Meng, Y. S.; Grey, C. P. Direct Evidence for High $\mathrm{Na}^{+}$Mobility and High Voltage Structural Processes in $\mathrm{P} 2-\mathrm{Na}_{\mathrm{x}}\left[\mathrm{Li}_{\mathrm{y}} \mathrm{Ni}_{\mathrm{z}} \mathrm{Mn}_{1-\mathrm{y}-\mathrm{z}}\right] \mathrm{O}_{2}(\mathrm{x}, \mathrm{y}, \mathrm{z}$ $\leq 1$ ) Cathodes from Solid-State NMR and DFT Calculations. J. Mater. Chem. A 2017, 5, 4129-4143. 